\title{
Kinematic first-order calving law implies potential for abrupt ice-shelf retreat
}

\author{
A. Levermann ${ }^{1,2}$, T. Albrecht ${ }^{1,2}$, R. Winkelmann ${ }^{1,2}$, M. A. Martin ${ }^{1,2}$, M. Haseloff ${ }^{1,3}$, and I. Joughin ${ }^{4}$ \\ ${ }^{1}$ Earth System Analysis, Potsdam Institute for Climate Impact Research, Potsdam, Germany \\ ${ }^{2}$ Institute of Physics, Potsdam University, Potsdam, Germany \\ ${ }^{3}$ University of British Columbia, Vancouver, Canada \\ ${ }^{4}$ Polar Science Center, APL, University of Washington, Seattle, Washington, USA
}

Correspondence to: A. Levermann (anders.levermann@pik-potsdam.de)

Received: 28 September 2011 - Published in The Cryosphere Discuss.: 12 October 2011

Revised: 30 January 2012 - Accepted: 21 February 2012 - Published: 13 March 2012

\begin{abstract}
Recently observed large-scale disintegration of Antarctic ice shelves has moved their fronts closer towards grounded ice. In response, ice-sheet discharge into the ocean has accelerated, contributing to global sea-level rise and emphasizing the importance of calving-front dynamics. The position of the ice front strongly influences the stress field within the entire sheet-shelf-system and thereby the mass flow across the grounding line. While theories for an advance of the ice-front are readily available, no general rule exists for its retreat, making it difficult to incorporate the retreat in predictive models. Here we extract the first-order large-scale kinematic contribution to calving which is consistent with large-scale observation. We emphasize that the proposed equation does not constitute a comprehensive calving law but represents the first-order kinematic contribution which can and should be complemented by higher order contributions as well as the influence of potentially heterogeneous material properties of the ice. When applied as a calving law, the equation naturally incorporates the stabilizing effect of pinning points and inhibits ice shelf growth outside of embayments. It depends only on local ice properties which are, however, determined by the full topography of the ice shelf. In numerical simulations the parameterization reproduces multiple stable fronts as observed for the Larsen A and B Ice Shelves including abrupt transitions between them which may be caused by localized ice weaknesses. We also find multiple stable states of the Ross Ice Shelf at the gateway of the West Antarctic Ice Sheet with back stresses onto the sheet reduced by up to $90 \%$ compared to the present state.
\end{abstract}

\section{Introduction}

Recent observations have shown rapid acceleration of local ice streams after the collapse of ice shelves fringing the Antarctic Peninsula, such as Larsen A and B (De Angelis and Skvarca, 2003; Scambos et al., 2004; Rignot et al., 2004; Rott et al., 2007; Pritchard and Vaughan, 2007). Lateral drag exerted by an ice-shelf's embayment on the flow yields back stresses that restrain grounded ice as long as the ice shelf is intact (Dupont and Alley, 2005, 2006). Ice-shelf disintegration eliminates this buttressing effect and may even lead to abrupt retreat of the grounding line that separates grounded ice sheet from floating ice shelf (Weertman, 1974; Schoof, 2007; Pollard and Deconto, 2009). The dynamics at the calving front of an ice shelf is thus of major importance for the stability of the Antarctic Ice Sheet and thereby global sea level (Cazenave et al., 2009; Thomas et al., 2004; Bamber et al., 2009; Winkelmann et al., 2012). Small-scale physics of calving events is complicated and a number of different approaches to derive rates of large- and small-scale calving events have been proposed (Bassis, 2011; Amundson and Truffer, 2010; Grosfeld and Sandhäger, 2004; Kenneally and Hughes, 2002; Pelto and Warren, 1991; Reeh, 1968). Different modes of calving will depend to a different extent on material properties of the ice and on the local flow field. As an example, considerable effort has been made to incorporate fracture dynamics into diagnostic ice shelf models (Rist et al., 1999; Jansen et al., 2010; Hulbe et al., 2010; Humbert et al., 2009; Saheicha et al., 2006; Luckman et al., 2011; Albrecht and Levermann, 2012). Furthermore ice fractures will alter the stress field and thereby also influence the flow 
field and calving indirectly (Larour et al., 2004; Vieli et al., 2006, 2007; Khazendar et al., 2009; Humbert and Steinhage, 2011).

Here we take a simplifying approach and seek the firstorder kinematic contribution to iceberg calving ignoring higher order effects as well as potential interactions of material properties with the kinematic field. We thus do not seek to understand the initiation, propagation and alteration of material defects of the ice such as crevasses or other fractures. While such properties are important for calving they will be comprised here in a proportionality factor which we seek to determine elsewhere, for example, by use of a fracture field as recently introduced (Albrecht and Levermann, 2012). These material properties and their alterations with the flow field are beyond the focus of this study. Instead we seek to describe the effect that the large-scale ice flow will have on the calving of an ice shelf with homogeneous material properties represented by this proportionality factor which is taken to be constant in this study. We further do not seek a comprehensive kinematic calving law which will most likely be of complicated nature; instead we determine the first-order contribution that is consistent with universal characteristics found in any ice shelf. Herein we follow a procedure commonly applied in theoretical elementary particle physics using an expansion of the unknown comprehensive calving law with respect to the eigenvalues of the large-scale spreading rate tensor (e.g. Peskin and Schroeder, 1995). General arguments often referred to as symmetry considerations then lead to the proposed parameterisation. We build on observations which found that the integrated largescale calving rate shows a dependence on the local ice-flow spreading rate (Alley et al., 2008) and that ice fronts tend to follow lines of zero across-flow spreading rates (Doake et al., 1998; Doake, 2001). Taking a macroscopic viewpoint, we propose a simple kinematic calving law applicable to threedimensional ice shelves, which is consistent with these observations (Figs. 1, 3 and 4) and unifies previous approaches in the sense that it extracts the first order-dependence on the spreading rate tensor.

\section{First-order kinematic contribution to calving}

Direct observations in Antarctica show that local calving rates increase with along-flow ice-shelf spreading-rates, $\dot{\epsilon}_{\|}$, i.e. the local spatial derivative of the horizontal velocity field along the ice-flow direction. Across different ice shelves the calving rate is proportional to the product of this along-flow spreading-rate and the width of the shelf's embayment (Alley et al., 2008). Dynamically this width strongly influences the spreading rate perpendicular to the calving front $\dot{\epsilon}_{\perp}$ (Fig. 2). Observations furthermore suggest that spreading perpendicular to the main flow controls formation and propagation of intersecting crevasses in the ice and thereby determines potential calving locations and influences calving rates (Ken-
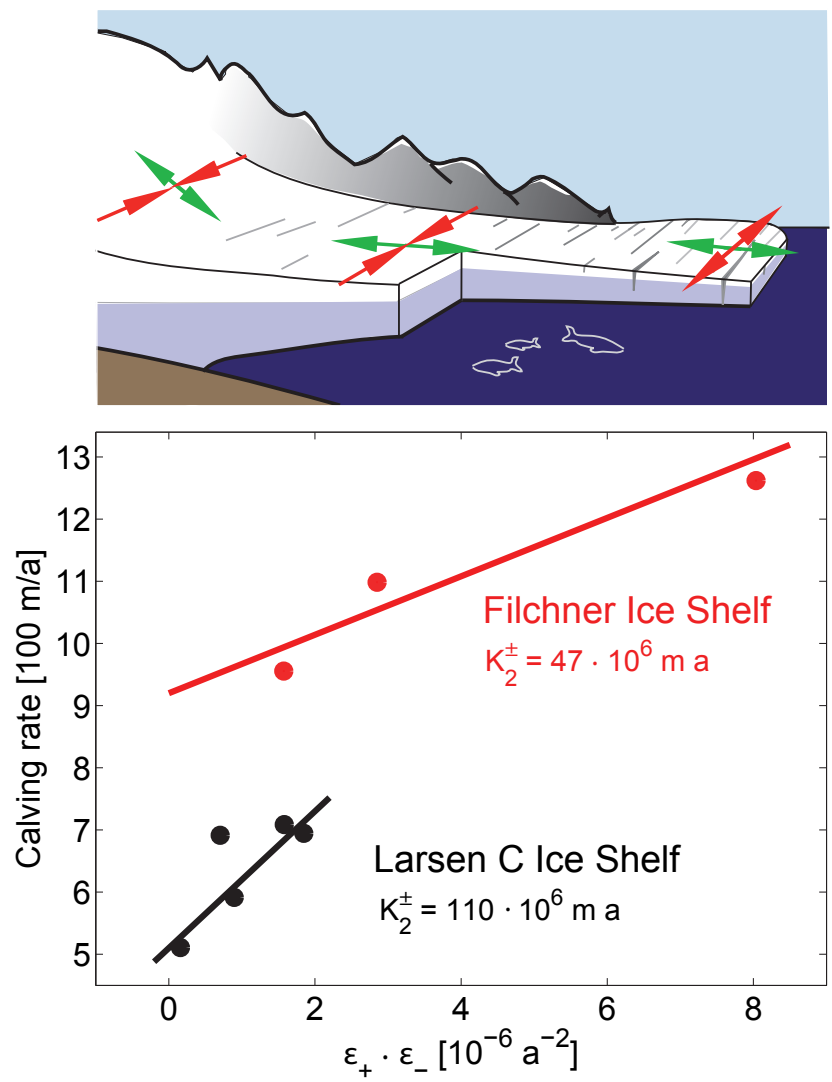

Fig. 1. Concept of eigencalving - Panel a: Schematic illustrating proposed kinematic calving law: the calving rate is proportional to the spreading rates in both eigendirections of the flow which generally coincide with directions along (green arrows) and perpendicular to (red arrows) the flow field. In the confined region of the ice shelf, e.g. in the vicinity of the grounding line, convergence of ice flow perpendicular to the main flow direction yields closure of crevasses, inhibits large-scale calving and stabilizes the ice shelf. Near the mouth of the embayment, the flow field expansion occurs in both eigendirections and large-scale calving impedes ice-shelf growth onto the open ocean. Panel b: The observed calving rate determined as the ice flow at the calving front increases with the product of the two eigenvalues which is proposed here as a firstorder kinematic calving law in Eq. (1). Details on the data can be found in appendix.

neally and Hughes, 2006). The reason is that negative $\dot{\epsilon}_{\perp}$ represents a convergence of ice at a certain location, which, if not too strong in magnitude, tends to close crevasses and inhibit large-scale ice-shelf calving. Positive $\dot{\epsilon}_{\perp}$, on the other hand, denotes expansion of ice, which tends to enhance ice weaknesses and thereby promotes calving. Such small-scale considerations are consistent with the large-scale observation (Doake et al., 1998) that ice-shelf fronts tend to follow lines of zero $\dot{\epsilon}_{\perp}$ (Doake, 2001).

All of this suggests that the relevant dynamic quantity for large-scale ice-shelf calving is the overall expansion of 

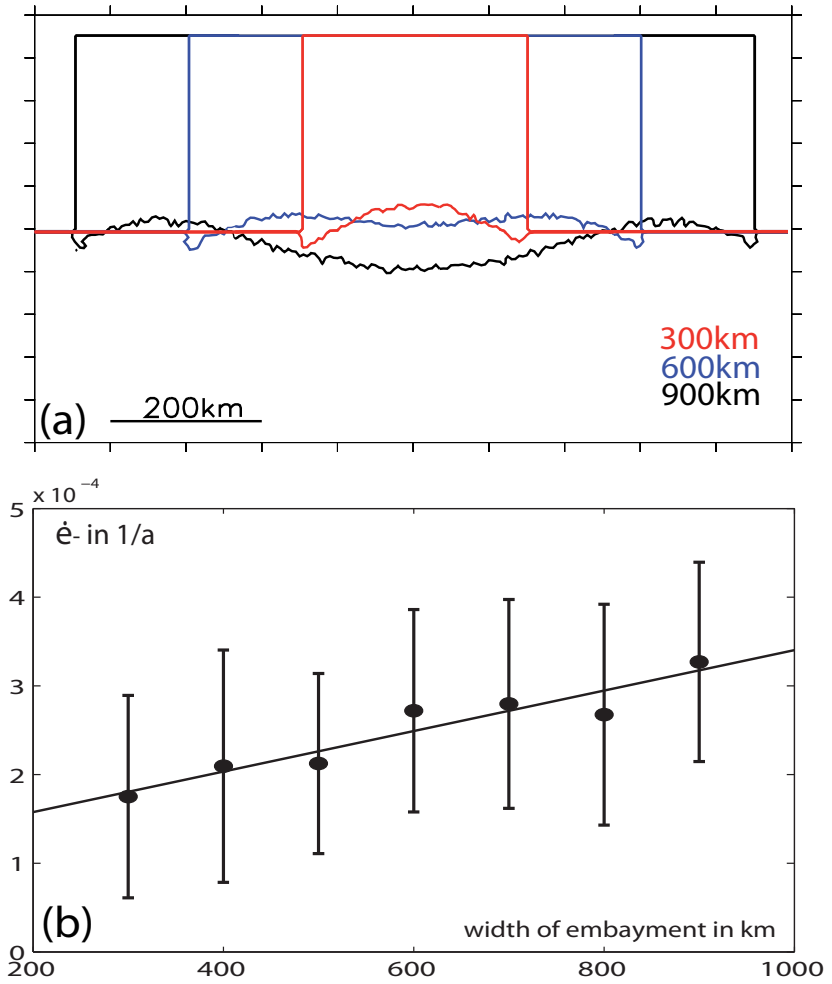

Fig. 2. Simplified set-up to investigate width dependence of second spreading-rate eigenvalue $\dot{\epsilon}_{-}$. Panel a: Geometry of basin and resulting calving front for different width of the rectangular embayment. Panel b: Quasi-linear relation between minor spreading rate eigenvalue $\dot{\epsilon}_{-}$in the center of the shelf at the calving front and the width of the embayment.

ice flow as represented by the determinant of the horizontal spreading-rate matrix. Mathematically the determinant is one of two rotationally-invariant characteristics of the horizontal spreading-rate matrix and thus particularly representative of isotropic effects in ice dynamics. The determinant is computed as the product of the spreading rates in the two principal directions of horizontal flow on ice shelves, $\dot{\epsilon}_{+} \cdot \dot{\epsilon}_{-}$. In most areas along the calving front, these so-called eigendirections will coincide with directions along and transversal to the flow, i.e. $\dot{\epsilon}_{+} \approx \dot{\epsilon}_{\|}$and $\dot{\epsilon}_{-} \approx \dot{\epsilon}_{\perp}$. We thus propose that in regions of divergent flow, where $\dot{\epsilon}_{ \pm}>0$, the rate of large-scale calving, $C$, is

$C=K_{2}^{ \pm} \cdot \dot{\epsilon}_{+} \cdot \dot{\epsilon}_{-}$for $\quad \dot{\epsilon}_{ \pm}>0$.

Here $K_{2}^{ \pm}$is a proportionality constant that captures the material properties relevant for calving. The macroscopic viewpoint of Eq. (1) comprises a number of small-scale physical processes of different calving mechanisms as well as intermittent occurrences of tabular iceberg release averaged over a sufficient period of time (see reference (Benn et al., 2007) for a detailed discussion).
Consistent with Eq. (1), we find that the product $\dot{\epsilon}_{+} \cdot \dot{\epsilon}_{-}$as derived from satellite observations (Joughin, 2002; Joughin and Padman, 2003) of the ice flow field of the ice shelves Larsen $\mathrm{C}$ and Filchner is indeed proportional to the calving rate estimated by the terminal velocity at the ice front (Fig. 1 and appendix for details on the data). Similar relations are found in the more recent surface-velocity field (Rignot et al., 2011) for the Larsen C-, Ronne- and Ross-ice shelves (Fig. 3) and the Amery- and Filchner-ice shelves (Fig. 4). Please note that spatially heterogeneous material properties are comprised in the proportionality constant $K_{2}^{ \pm}$. It is thus neither to be expected that the relations shown in Figs. 1-4 are linear nor that the slopes provided as regression lines are equal. In fact the slopes for the relatively narrow ice shelves Amery and Filchner are considerably smaller than those for the other comparably broader shelves. (Note that in using the terminal velocity as an indicator for calving rate, we assume that changes in ice velocity and glacier length are small in relation to the calving rate and the changes in the ice-front position.)

Equation (1) can be considered the first-order kinematic contribution to calving under three basic assumptions: (a) stable calving fronts exist, (b) material properties of ice near the calving front can be assumed to be isotropic to leading order and (c) of all available kinematic properties it is the vertically averaged spreading rate tensor on which calving depends to leading order. In other words, if a calving law is sought that assumes isotropic material properties of the ice and one asks for the dependence of this law on the horizontal spreading rate field, then such a law can be expanded in terms of the the eigenvalues of the spreading rate tensor as follows:

$C=K_{1}^{+} \cdot \dot{\epsilon}_{+}+K_{1}^{-} \cdot \dot{\epsilon}_{-}+K_{2}^{+} \cdot \dot{\epsilon}_{+}^{2}+K_{2}^{-} \cdot \dot{\epsilon}_{-}^{2}+K_{2}^{ \pm} \cdot \dot{\epsilon}_{+} \cdot \dot{\epsilon}_{-}+\ldots$

with parameters $K_{i}^{ \pm}$which may depend on the material properties of the ice. In this formal expansion a number of terms need to be dismissed on the ground of large-scale physical reasoning. Since the largest eigenvalue $\dot{\epsilon}_{+}$generally increases within the ice shelf when approaching the grounding line upstream (compare for example Fig. 5 c), $K_{1}^{+}$has to vanish or otherwise ice shelves would generally not be stable at all. On the other hand, a non-vanishing $K_{1}^{-}$would mean that calving is determined mainly by ice divergence across the main flow direction. While we argue that this is indeed a relevant quantity, observations (Fig. 1 and reference (Alley et al., 2008)) suggest that there has to be a leading role of $\dot{\epsilon}_{+}$. The same arguments make it necessary that both $K_{2}^{+}$and $K_{2}^{-}$vanish. Thus the first-order term of such a law has to be the one associated with $K_{2}^{ \pm}$as we propose in Eq. (1). Please note that Eq. (1) is not in contradiction with the relation derived from Amundson and Truffer (2010). They computed the steady-state calving rate that is required to balance the ice-front advance as governed by the Shallow Shelf Approximation, i.e. within the framework of continuum mechanics. 

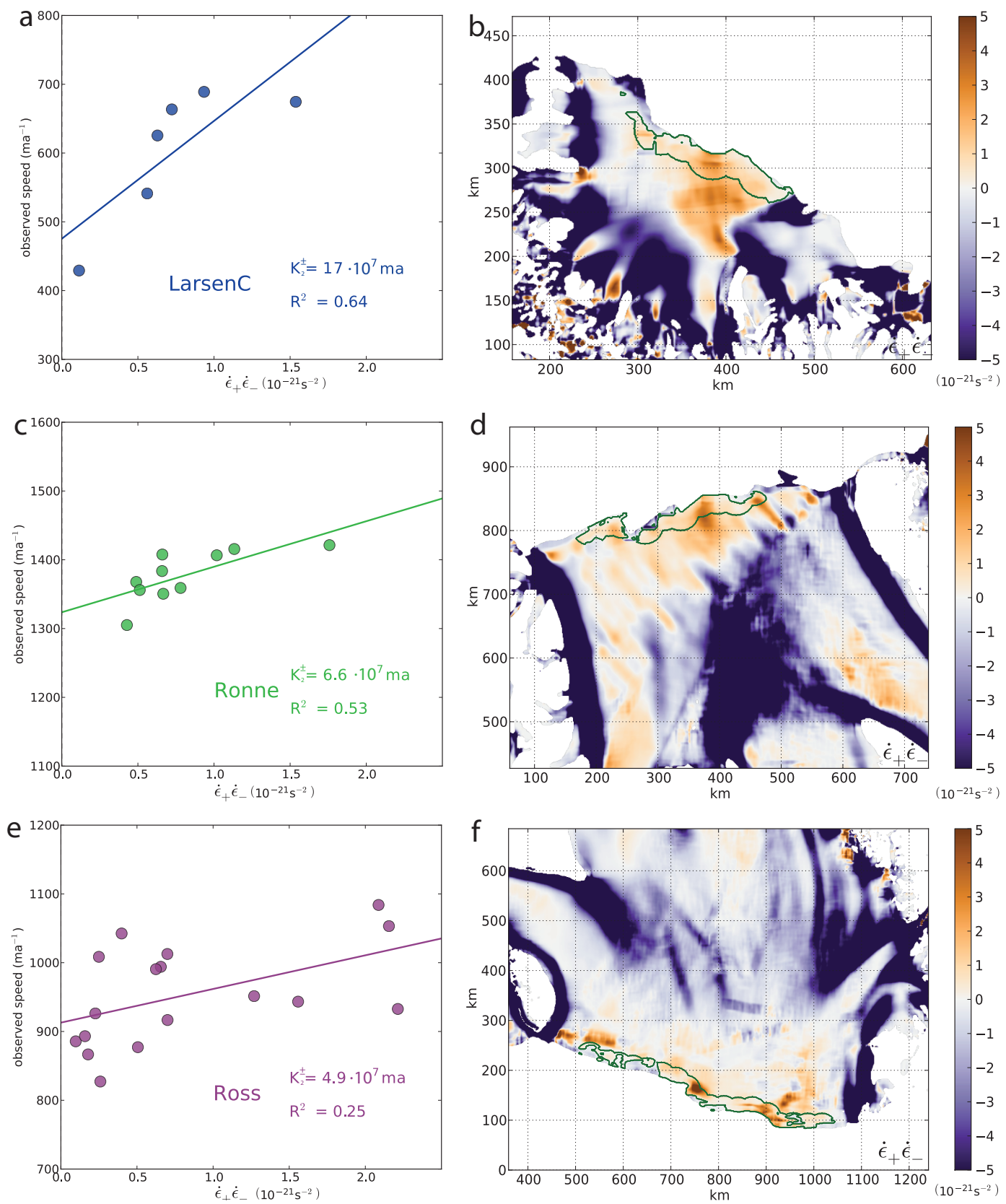

Fig. 3. Eigencalving relation for the comparably broad topographies of Larsen-, Ronne- and Ross-ice shelves as derived from the surface velocity data set by Rignot et al. (2011).

They obtain a linear relation between the trace of the spreading rate tensor and the calving rate which is required for an ice front to be in equilibrium with the flow field. While this diagnostic relation needs to be fulfilled by a steady ice front, it was not derived as a time-dependent calving law. Figure 8 shows that this relation holds well in the center-line of an ice shelf where the approach is well justified. In the simulations the eigencalving law of Eq. (1) was applied which means that both the trace and the determinant of the spreading rate tensor are proportional to the calving rate in these places.

\section{Eigencalving yields stable fronts of varying thickness}

It has to be noted that not all calving will fulfill the three assumptions above. For example, some calving processes might mainly depend on the vertical shear within the ice. In cases where the assumptions are met, Eq. (1) can be applied both in analytic calculations and numerical simulations of ice-shelf dynamics. Here it was implemented into the Potsdam Parallel Ice Sheet Model (PISM-PIK) (Winkelmann et al., 2011) for the Ross Ice Shelf (Please find more details 

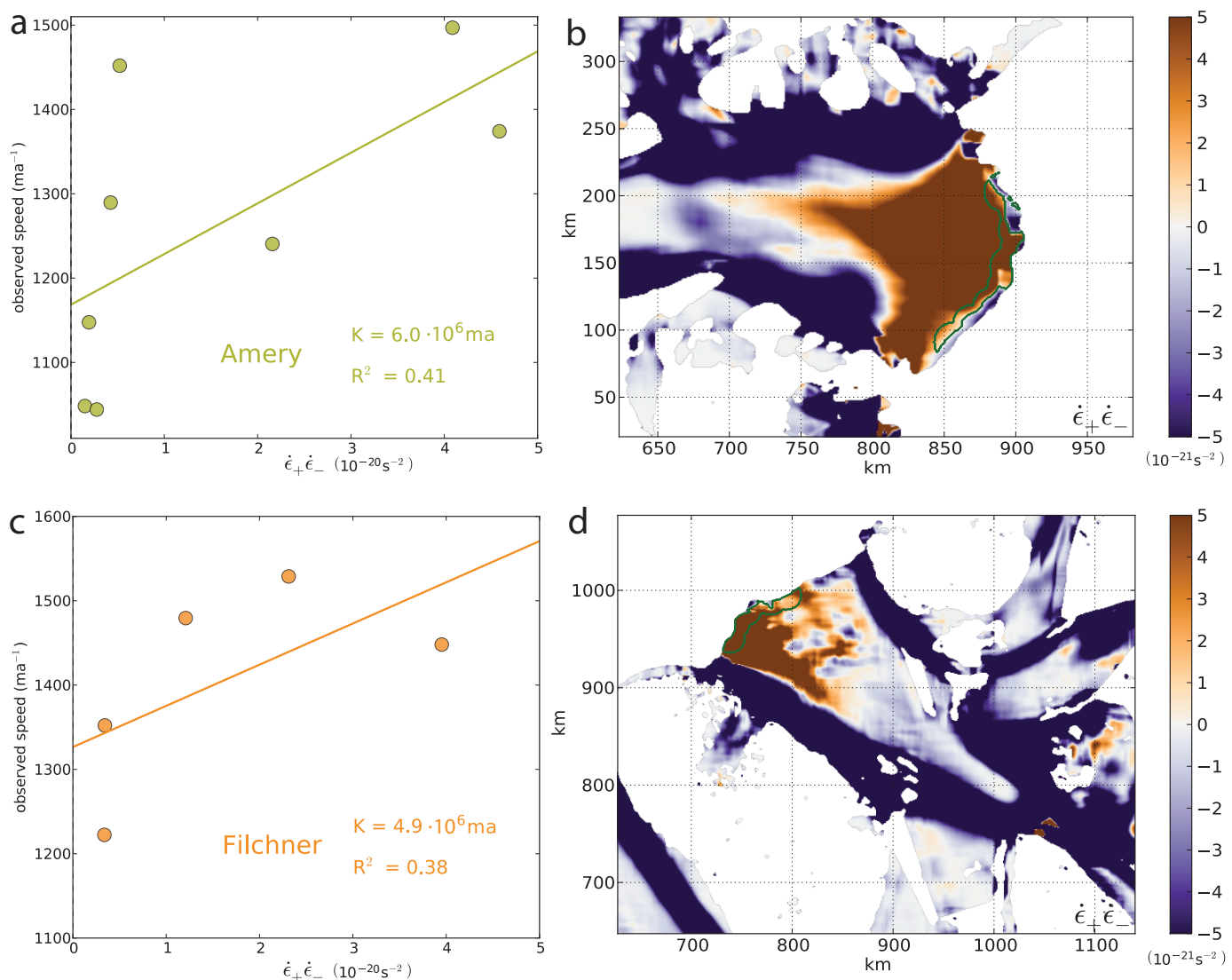

Fig. 4. Eigencalving relation for the comparably narrow topographies of Amery- and Filchner-ice shelves as derived from the surface velocity data set by Rignot et al. (2011).

on the experimental set-up in the appendix.) For low values of the proportionality constant, $K_{2}^{ \pm}$, calving is not sufficient to ensure a stable calving front (Fig. 5a, b). Above a certain threshold, $K^{*} \approx 1 \times 10^{9} \mathrm{ma}$, the calving front is dynamically stable, i.e. the variability of the ice front becomes small (compare gray lines adjacent to the calving front in Figs. 69). The lack of bottom drag induces a maximum spreading rate along the ice-flow direction downstream of, but close to, the grounding line (Fig. 5c). Thus, as argued above, a calving rate which depends only on $\dot{\epsilon}_{+}$would generally increase towards the grounding line so that no stable ice-shelf front would develop. Stability arises through the dependence on the overall expansion of the velocity field, which is negative for most of the shelf area (Fig. 5d) and prohibits calving there. Spreading rate fields and thereby areas of potential calving according to Eq. (1) are strongly influenced by the geometry of the shelf ice. The proposed kinematic calving law thereby incorporates the effect of pinning points, such as Roosevelt Ice Rise (RIS) amidst the Ross Ice Shelf. These pinning points produce convergence of ice flow and thereby stabilize the calving front. In contrast to these regions of convergence, ice flow strongly expands towards the mouth of the shelf's embayment. Here, calving rates strongly increase and hinder ice-shelf growth outside the bay.

For the Larsen A and B Ice Shelves, application of Eq. (1) in numerical simulations with PISM-PIK yields a stable calving front that compares well with the observed state before 1999 (Fig. 6a). These fronts are obtained with the same proportionality factor $K_{2}^{ \pm}=5 \times 10^{9}$ ma as used for the Ross Ice Shelf. Eigencalving thus allows to reproduce calving fronts with varying ice thickness as also found in simulations of the whole Antarctic Ice Sheet (Martin et al., 2011).

\section{Multiple stable fronts and abrupt transitions between them}

Inverse computation of ice softness prior to the major disintegration of Larsen B Ice Shelf in 2002 suggested regions of strongly weakened ice rheology along the fringing pinning points of Robertson Island (RI), Seal Nunataks Islands (SN) in the North East and Jason Peninsula (JP) and Cape Disappointment (CD) in the South West (Khazendar et al., 2007; Vieli et al., 2006). Instantaneous introduction of icefree rifts in the vicinity of these locations for the minimal 

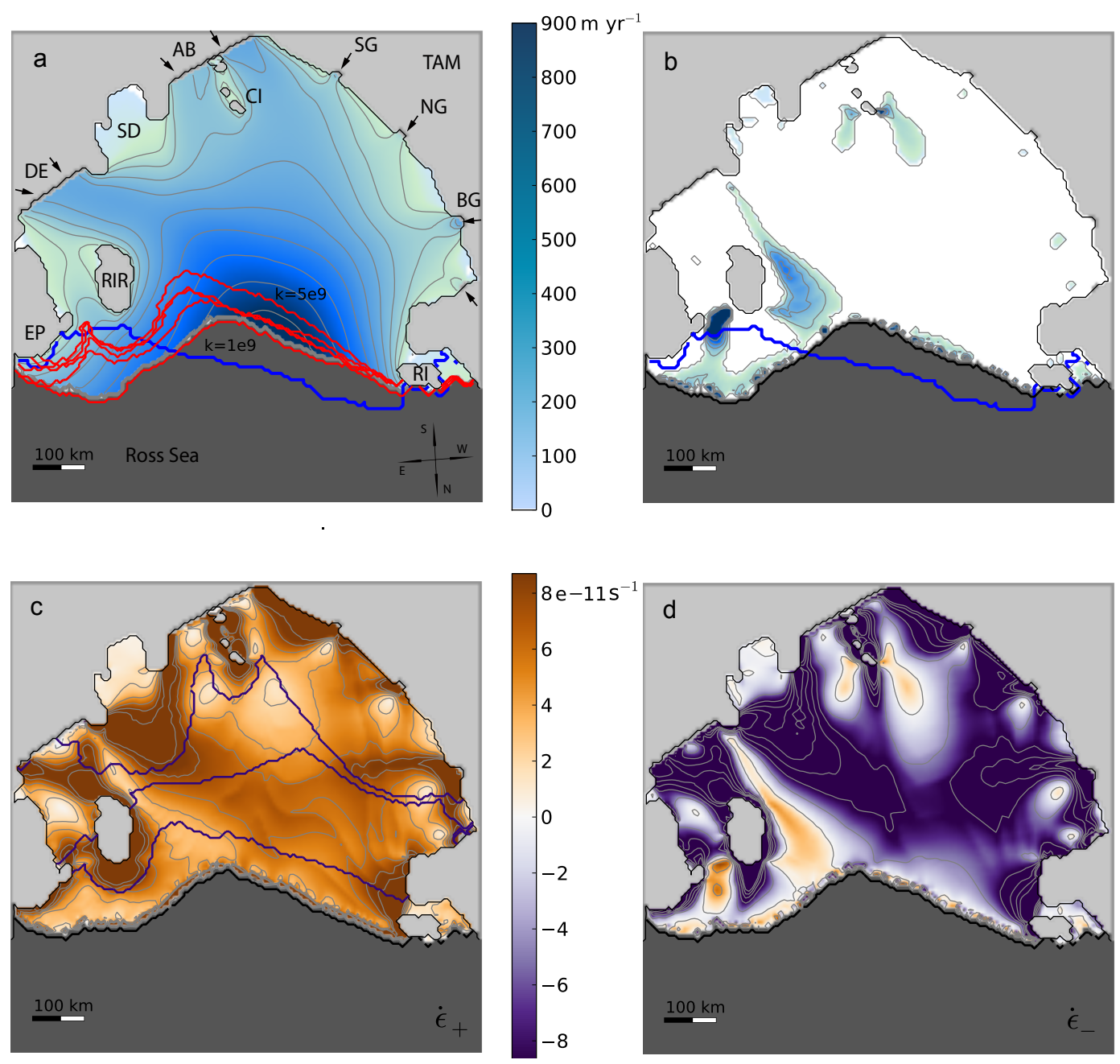

Fig. 5. Kinematic calving law applied to Ross Ice Shelf. Panel a: Modeled ice velocity field. Red lines represent stable calving fronts for different values of $K_{2}^{ \pm}=1,2,3,4,5 \times 10^{9}$ ma. Blue line represents the observed calving front from the BEDMAP project (Lythe et al., 2001); since the 2001 publication of the BEDMAP data the observed calving front has moved closer towards the modeled front. Panel b: Modeled potential calving rate for $K_{2}^{ \pm}=1 \times 10^{9}$ ma according to Eq. (1). In most areas of the ice shelf potential calving rate is negative due to compression in at least one eigendirection. Largest (panel c) and smallest (panel d) eigenvalue of the strain rate field $\dot{\epsilon}$ for $K_{2}^{ \pm}=1 \times 10^{9}$ ma. Lines indicate three stable calving fronts of the Ross Ice Shelf as obtained by Eq. (1) with $K_{2}^{ \pm}=5 \times 10^{9}$ ma following the introduction of rifts similar to the simulations in Fig. 7. Light gray shading represents grounded ice and dark gray shading represents ice-free ocean which are both not modeled here.

duration of one time step strongly alters the stress field within the ice shelf (Fig. 6). Consequently spreading rates and potential calving rates are changed and the ice shelf undergoes an abrupt transition towards a second stable state (Fig. 7 and animation in SI).

Further perturbation or different initialization of the ice shelf area reveals a third stable front. These states are dynamically robust with respect to the proportionality constant $K_{2}^{ \pm} \geq K^{*}$ and compare reasonably well with observed stages of Larsen B disintegration between 1998 and 2002 (Fig. 7). The corresponding calving fronts tend to follow lines of zeroice-flow-compression at $\dot{\epsilon}_{-}=0$, as had been suggested by earlier reconstructions of $\dot{\epsilon}_{-}$from observed ice velocity data (Doake et al., 1998; Doake, 2001). These contours of $\dot{\epsilon}_{-}=0$ change with ice-shelf geometry which makes multiple dynamically stable fronts possible. These ice fronts can, however, not be inferred simply from a static velocity field, but evolve under the dynamical interaction of ice flow field and calving rate. In regions where the ice flow can be approximated by the SSA-equation, the calving rate at a stable front in fact has to fulfill the linear relation with the trace of the spreading rate tensor. This is indeed the case as Fig. 8 shows for an idealized rectangular shelf geometry. 

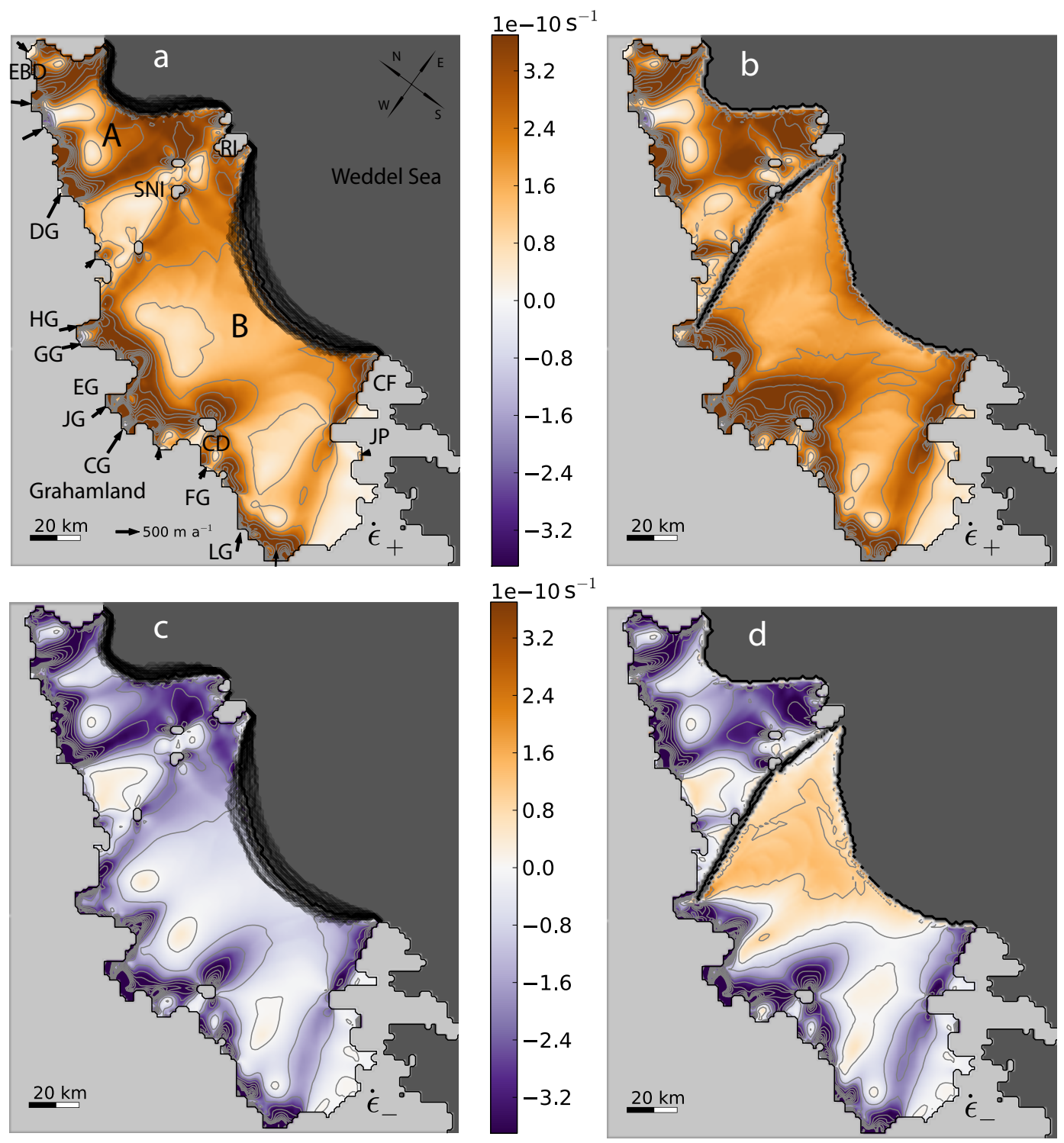

Fig. 6. Kinematic calving law applied to Larsen A and B Ice Shelves with $K_{2}^{ \pm}=1 \times 10^{9}$ ma. Change in spreading-rate components in eigendirections due to instantaneous introduction of ice rift of $2000 \mathrm{~m}$ width, which separates ice flow from its pinning points. While the spreading rate in the direction of maximum ice flow $\dot{\epsilon}_{+} \approx \dot{\epsilon}_{\|}$does not change significantly (panel a $\rightarrow$ b). Spreading rate $\dot{\epsilon}_{-} \approx \dot{\epsilon}_{\perp}$ changes sign near the rift (panel $\mathrm{c} \rightarrow \mathrm{d}$ ) and thereby initiates an abrupt transition towards a second stable state as shown in Fig. 7c. Light gray shading represents grounded ice and dark gray shading represents ice-free ocean which are both not modeled here. Gray lines adjacent to the calving front represents the variability of the front in the equilibrium simulation. Time step for plotted front-front positions is two years.

Rapid retreat as governed by Eq. (1) occurs within several months after the perturbation depending on the value of $K_{2}^{ \pm}$(compare animation in SI). The analysis of satellite data show that the 2002-Larsen-B disintegration was not caused by localized calving near the ice front but by emergence of surface ponds which weakened the ice shelf and caused a sudden collapse (MacAyeal et al., 2003; Glasser and Scambos, 2008). Our simulations thus do not provide an explanation of this event but show that the emerging stable calving fronts are consistent with the calving, which is governed by the first-order kinematic law (Eq. 1) and may explain temporal stability of these fronts.

Simulations of the Ross Ice Shelf reproduce the presently observed calving front and suggests two additional stable front position (Fig. 5c). These are associated with reductions in ice-shelf areas by $37 \%$ and $60 \%$. Back stress onto the West Antarctic Ice Sheet in these states is reduced by up to $90 \%$ (Fig. 9). 

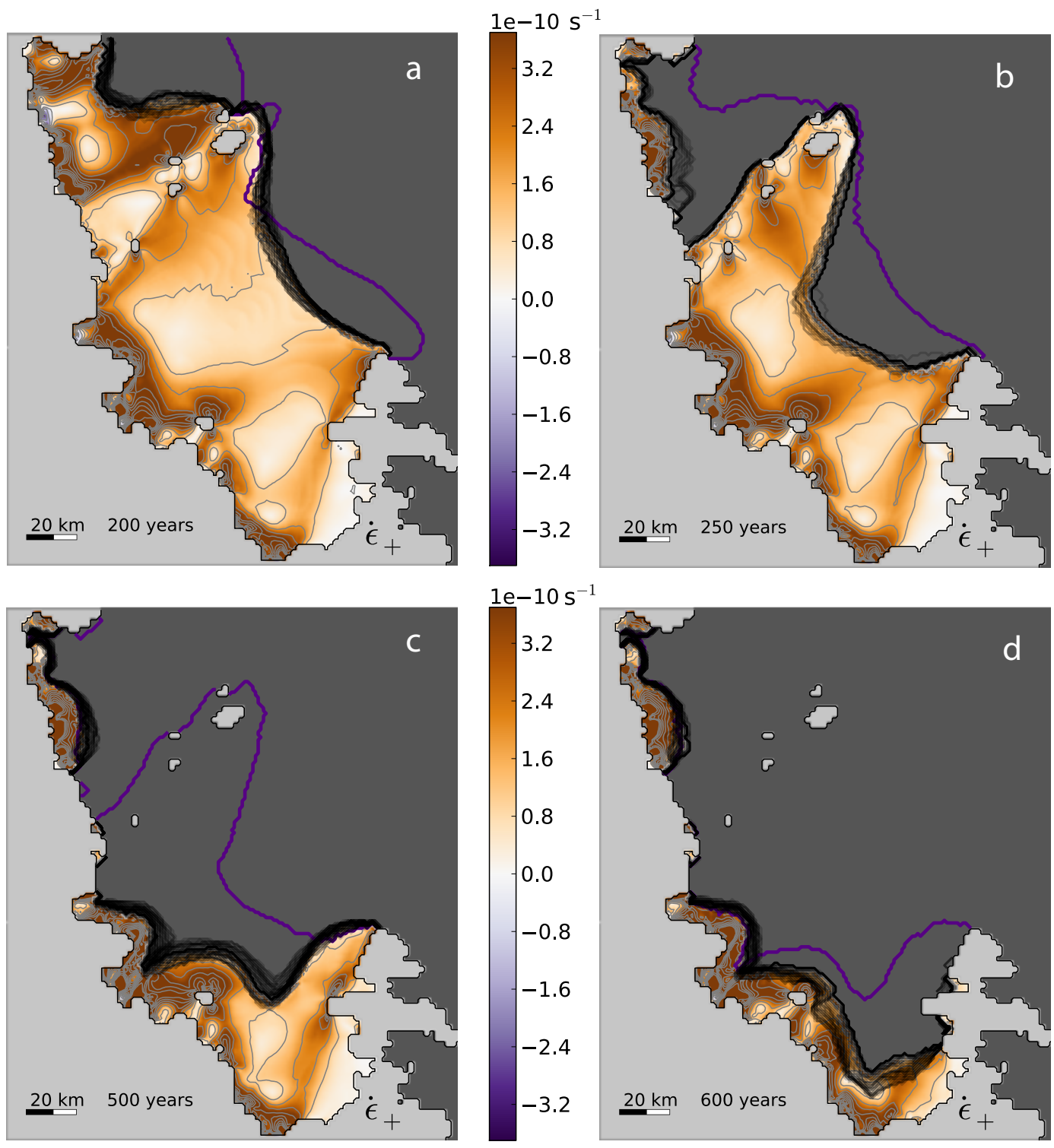

Fig. 7. Simulation of multiple stable calving front position of ice shelves Larsen A and B. Abrupt transitions between the states can be triggered by instantaneous introduction of ice rifts of $2000 \mathrm{~m}$ width (two grid cells) for one time step along the purple lines (compare also animation in SI). Shading represents strongest spreading rate $\dot{\epsilon}_{+} \approx \dot{\epsilon}_{\|}$. Gray lines adjacent to the calving front represents the variability of the front in the equilibrium simulation. Time step for plotted front-front positions is two years. Panel a: Calving front after 100 years of free propagation (purple line) is stabilized by calving rate according to Eq. (1) near the observed 1998 extension (compare Fig. 2). Panel b: Initialization of ice front at the year 1998 positions (purple line) plus rifts in the southern parts of Larsen A, induces a collapse of Larsen A Ice Shelf and a retreat of the Larsen B front to the 1999 position. Panel c: Rift applied along northern margin of Larsen B yields a second stable state of the Larsen B ice front similar to the observed 2002 position. Panel d: Rift applied along southern margins of Larsen B yields third stable state with strongly reduced ice-shelf area.

\section{Discussions and conclusions}

Reliable projection of the evolution of the Antarctic Ice Sheet under future climate change need to take calving-front dynamics into account. We present a calving law that reproduces presently observed ice fronts of ice shelves with strongly varying ice thickness, e.g. the Larsen Ice Shelf and the Ross Ice Shelf. The calving law has been applied in simulations of the entire Antarctic Ice Sheet (Martin et al., 2011) where it produces a realistic ice front for all major ice shelves. The calving law of Eq. (1) represents the first-order kinematic contribution of calving under the assumption that calving depends kinematically to first-order on the horizontal strain rate field and that ice properties are to first-order 


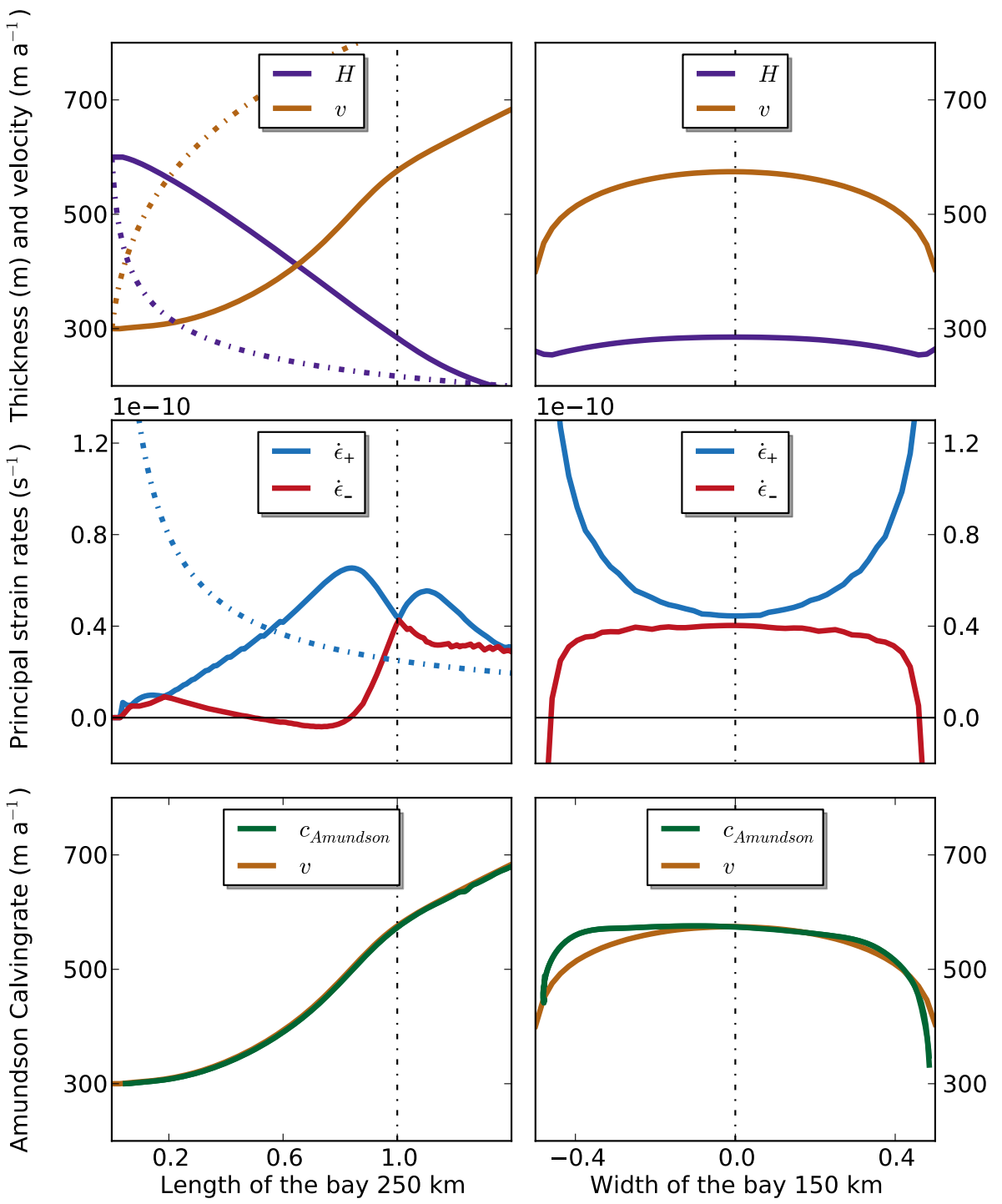

Fig. 8. Comparison with relation derived for steady-state calving rate from the SSA-equation (Amundson and Truffer, 2010). Properties for an ice shelf confined in a rectangular narrow basin of $150 \times 10^{3} \mathrm{~m}$ width and $250 \times 10^{3} \mathrm{~m}$ length with time-dependent calving according to Eq. (1). Left column: properties for the center-line along the main flow direction. Right column: properties for a cross-section at the mouth of the embayment. Shown are ice thickness and speed ( $H$ and $v$, top) along with the spreading rate components (middle). Analytic solutions for an unconfined ice shelf are provided as dashed curves. The lower panels compare the steady-state estimate of the calving rate as computed from Amundson and Truffer (2010) with the ice speed. While the two compare very well along the center-line, the estimate deviates slightly near the margin where buttressing becomes important and the assumption that the ice velocity has the same direction as the gradient of $\mathrm{H}$ becomes slightly less accurate. The good agreement shows that at the calving front at which the Amundson and Truffer (2010)-assumptions hold, the calving rate has to be proportional to the trace as well as to the determinant of the spreading rate tensor.

isotropic. Not all calving has to fulfill these assumptions. While isotropic material properties can be captured in the proportionality constant $K_{2}^{ \pm}$, ice can be anisotropic near the ice front. Furthermore, some calving processes might mainly depend on the vertical shear within the ice as opposed to the horizontal strain rate field. The reasoning and conditions under which Eq. (1) can be considered a calving law are discussed in detail in the introduction and Sect. 2. Under these conditions, we propose eigencalving as a first-order law for large-scale calving comprising a number of small-scale processes. For a comprehensive description of calving front dynamics our approach may be complemented by additional processes that are not captured by Eq. (1) . 

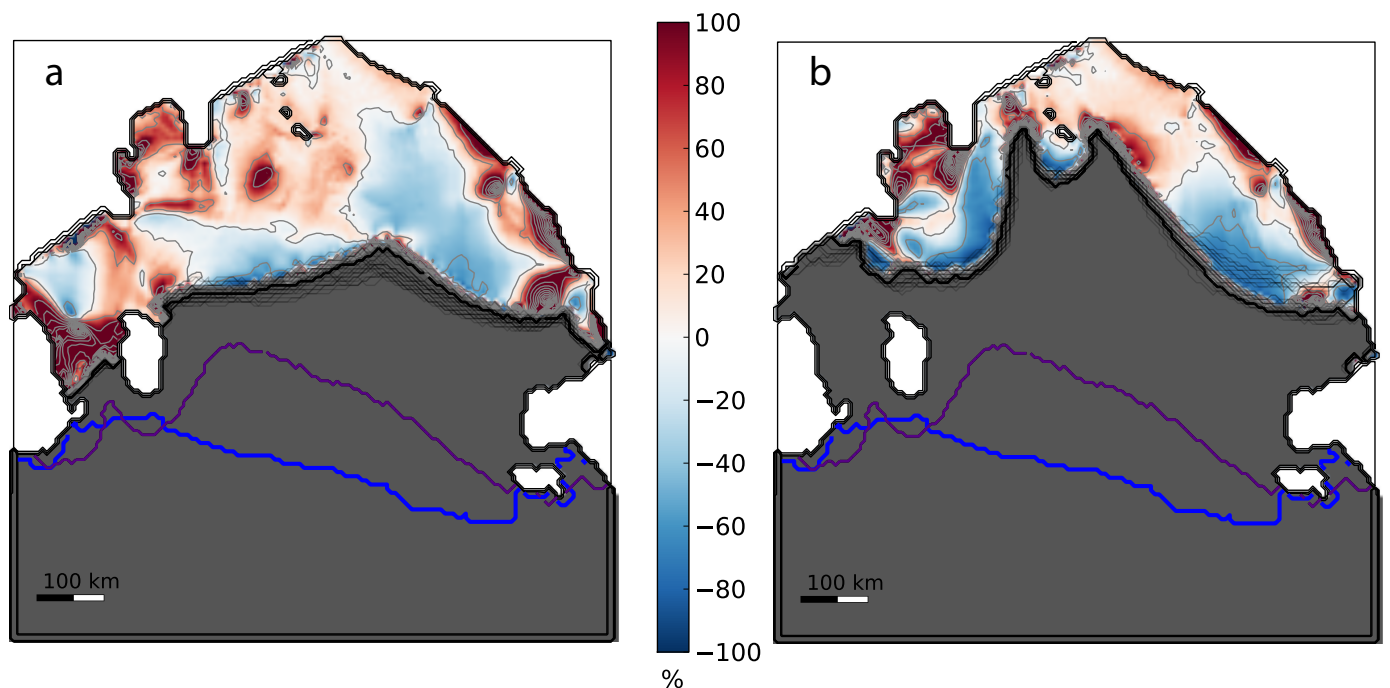

Fig. 9. Additional stable calving front of the Ross Ice Shelf under eigencalving. Colors represent relative change in longitudinal stress between the modeled presently observed extent of the ice shelf (thick blue line) and the second and third stable states of the ice shelf. Gray lines adjacent to the calving front represents the variability of the front in the equilibrium simulation. Panel a: State with $37 \%$ reduced ice shelf area. Panel b: State with $60 \%$ reduced ice shelf area compared to the modeled present-day situation. Back stress onto the West Antarctic Ice Sheet in these states is reduced by up to $90 \%$.

\section{Appendix A}

\section{Radar data}

Ice-velocity fields for the computation of the spreading rates were derived from radar satellite data. In the case of Fig. 1 SAR speckle tracking algorithms were used and provided on a regular grid of grid length $1 \mathrm{~km}$ in Polar Stereographic projection with $71^{\circ} \mathrm{S}$ as the latitude of true scale (Joughin, 2002). Data are based on observations of the years 2006-2008 for Larsen C (JAXA ALOS L-band SAR) and 1997-2000 for Filchner-Ronne (Joughin and Padman, 2003) (RADARSAT Antarctic Mapping Mission). In the case of Figs. 3 and 4 they were assembled from multiple satellite interferometric synthetic-aperture radar data acquired during the International Polar Year 2007 to 2009 (Rignot et al., 2011). Strain rates were computed as the spatial derivative of the velocity field (neglecting projection errors) with a centered scheme (along the boundaries inward). In order to reduce the effect of undulations of length scale 5-8 km that are due to the measuring and processing technique, we long-pass filtered the velocity field with a two-dimensional sliding window of $21 \times 21 \mathrm{~km}$ size. In order to avoid data from grounded ice only data points with a velocity magnitude larger than a threshold of $10 \mathrm{~m} \mathrm{yr}^{-1}$ within this window were taken into account. Independent data points were computed in $30 \mathrm{~km}$ sections $(15 \mathrm{~km}$ for the more narrow ice shelves Amery and Filchner) along the ice shelf front in which average velocities and horizontal spreading rate eigenvalues were computed. Figures 1, 3 and 4 show the relation between ice velocity at the ice front (assumed to be a measure for the calving rate for a steady calving front) and the product of the spreading rate eigenvalues, i.e. the determinant of the spreading rate matrix for the respective ice shelves.

\section{Appendix B}

\section{Brief model description of PISM-PIK}

In this study, we apply a derived version of the opensource Parallel Ice Sheet Model version stable 0.2 (PISM, see user's manual (PISM-authors, 2012) and model description paper (Bueler and Brown, 2009)). Starting from PISM stable 0.4 most features of the Potsdam Parallel Ice Sheet Model (PISM-PIK, Winkelmann et al. (2011)) have been integrated in the openly available PISM code. It is a thermomechanically coupled model developed at the University of Alaska, Fairbanks, USA. The thickness, temperature, velocity and age of the ice can be simulated, as well as the deformation of Earth underneath the ice sheets. Verification of the code with exact analytical solutions were used to test its numerical accuracy (Bueler et al., 2007). Ice softness, $A\left(T^{*}\right)$, is determined following Paterson and Budd (1982). PISM generally applies a combination of the Shallow Ice Approximation (SIA) and the Shallow Shelf Approximation (SSA) (Morland, 1987; Weis et al., 1999) to simulate grounded ice. In all simulations presented here ice is floating and thus the velocity field is computed by application of SSA only. Numerical solutions of the SSA-matrix inversion were obtained 
using the Portable Extensible Toolkit for Scientific computation (PETSc) library (Balay et al., 2008).

Compared to PISM (version stable 0.2), the Potsdam Parallel Ice Sheet Model (PISM-PIK) as used here, applies two major modifications to the original version of PISM. First, a subgrid scale representation of the calving front was implemented in order to be able to apply a continuous calving rate (compare ref. (Albrecht et al., 2011) for a detailed description). Secondly, we introduced physical boundary conditions at the calving front to ensure that the non-local velocity calculation yields a reasonable and physically based distribution of the velocity throughout the ice shelf which is crucial for this study. For a full description of PISM-PIK please confer ref. (Winkelmann et al., 2011). The models performance under present day boundary conditions is provided in ref. (Martin et al., 2011).

\section{Appendix C}

\section{Experimental setup of ice-shelf simulations}

In the experimental setups used in this study an ice flow from a region of grounded ice is prescribed by Dirichlet boundary conditions (fixed ice thickness and velocity) and the dynamically evolving ice-shelf is computed according to SSA. Simulations have all been integrated into equilibrium for several thousand of years. Grounded ice was not taken into account (margins fixed) and in order to ensure that no grounding occurs during the simulation the bathymetry within the confining bay is set to $2000 \mathrm{~m}$.

\section{C1 Ross Ice Shelf (RIS)}

The Ross Ice Shelf setup has been derived from data used for the ice-shelf model-intercomparison, EISMINT II - Ross (MacAyeal et al., 1996). Ice thickness, surface temperature and accumulation rate of the main part of the Ross ice shelf were applied on a $6.82 \mathrm{~km}$ resolution grid (Fig. 5). The computational domain in total measures $1000 \times 1000 \mathrm{~km}^{2}$, approximately between $150^{\circ} \mathrm{W}$ and $160^{\circ} \mathrm{E}$, as well as between $75^{\circ} \mathrm{S}$ and $85^{\circ} \mathrm{S}$. Inflow velocities at the grounding line have been prescribed from RIGGS data (Ross Ice shelf Geophysical and Glaciological Survey (Thomas et al., 1984; Bentley, 1984)). Broad ice streams drain into the shelf over the Siple Coast (SC) in the south-east draining the West Antarctic Ice Sheet (WAIS), smaller ones urge through the Transantarctic Mountains (TAM) in the west, e.g. the Byrd Glacier (BG), feeding the Ross Ice Shelf with ice from East Antarctica. Properties in the grounded part are held constant during the simulation and friction is prescribed at the margin. The Roosevelt (RIR) and Crary Ice Rises (CIR) are prescribed as elevations of the bedrock. RIGGS velocity data, acquired at a few hundred locations in the years 1973-1978, has been used to validate the SSA-velocity calculations of the model. Com- pared to the original data the setup has been slightly modified in the vicinity of the outer pinning points according to BEDMAP (Lythe et al., 2001) data, such as Ross Island (RI) in the west, where the $3894 \mathrm{~m}$ high volcano Mount Erebus can be found, and the Edward-VII-Peninsula (EP) with Cape Colbeck (CC) in the east. These areas had been roughly extrapolated in the original model intercomparison, but they are crucial in our studies in finding a more realistic steady state of the calving front position and are thus more realistically represented in our simulations.

\section{C2 Larsen Ice Shelves A and B}

Our computational setup incorporates part A and B of the Larsen Ice Shelf which has undergone some dramatical retreats in the last two decades (Fig. 7). These comparably small ice shelves are fringing the Antarctic Peninsula between $64.5^{\circ} \mathrm{S}-66^{\circ} \mathrm{S}$ and $63^{\circ} \mathrm{W}-59^{\circ} \mathrm{W}$. Surface elevation and velocity data have been raised in the Modified Antarctic Mapping Mission (MAMM), by the Byrd Center group (Liu et al., 1999; Jezek et al., 2003). We apply them on a $2 \mathrm{~km}$ grid as provided by Dave Covey from the University of Alaska, Fairbanks (UAF). The computational domain is $200 \times 170 \mathrm{~km}^{2}$ and has been re-gridded to $1 \mathrm{~km}$ resolution. Gaps in the data were filled as average over existing neighboring values up to the ice front in the year 1999 for Larsen B (Ice front of Larsen A at position of about beginning 1995). The surface temperature (Comiso, 2000) and accumulation data (Van de Berg et al., 2006) has been taken from presentday Antarctica SeaRISE Data Set on a $5 \mathrm{~km}$ grid (Le Brocq et al., 2010), regridded to $1 \mathrm{~km}$ resolution. Ice shelf thickness is calculated from surface elevation, assuming hydrostatic equilibrium. The grounding line was expected to be located where the surface gradient exceeds a critical value (also for ice rises). Observed velocities and calculated ice thicknesses were set as a Dirichlet condition on the supposed grounding line in inlet regions simulating the ice stream inflow through the mountains. Six important tributaries can be located along the western grounding line, from south to north: Leppard Glacier (LG), Flask Glacier (FG), Crane Glacier (CG), Evans Glacier (EG) and Hektoria Glacier (HG). Drygalsky Glacier (DG) is feeding Larsen A north of the Seal Nunataks Islands (SNI) with the prominent Robertson Island (RI) that separate Larsen A and B Ice Shelves; Larsen B and C are physically divided by Jason Peninsula (JP). Larsen $\mathrm{C}$ is much larger and not taken into account in these studies. There, ice is cut off at the coastline south of Cape Framnes (CF). 


\section{Appendix D}

\section{Animation of simulation of Larsen A and B Ice Shelves}

The animation in this SI shows the smaller eigenvalue of the spreading rate matrix $\dot{\epsilon}_{-}$for the Larsen A and B Ice Shelves. Time is plotted as a running number in years of integration. The animation begins without any calving starting from a steady state with front position comparable to the observed situation of the year 1997. Consequently, the shelves grow out of the embayment where it builds up a region with strongly positive $\dot{\epsilon}_{-}$. After 100 years eigencalving (following Eq. (1) with $K_{2}^{ \pm}=1 \times 10^{9}$ ma is introduced which stabilizes the calving front at the position of 1997. After another 100 years an ice rift along the margins of Larsen A of 2-gridbox-width is introduced by removing ice there for one time step. As a consequence the calving front of Larsen A spontaneously retreats to a new remanent position. This affects the calving front of Larsen B which stabilizes near the observed position of the year 1999. Further rifts are introduced along the north-east shear margin of Larsen B Ice Shelf and the south-west margin of the Larsen B Ice Shelf successively. The resulting remanent steady state calving front positions are similar to the observed ones after March 2002.

\section{Supplementary material related to this article is available online at: http://www.the-cryosphere.net/6/273/2012/ tc-6-273-2012-supplement.zip.}

Acknowledgements. We would like to thank Ed Bueler and Constantine Khroulev for invaluable help with the PISM model and David M. Holland for useful comments on the work. The study was funded by the German National Academic Foundation, the German Leibniz association and a doctoral fellowship of the University of British Columbia.

Edited by: I. M. Howat

\section{References}

Albrecht, T. and Levermann, A.: Fracture field for largescale ice dynamics, Journal of Glaciology, 58, 165-176, doi:10.3189/2012JoG11J191, 2012.

Albrecht, T., Martin, M., Haseloff, M., Winkelmann, R., and Levermann, A.: Parameterization for subgrid-scale motion of ice-shelf calving fronts, The Cryosphere, 5, 35-44, doi:10.5194/tc-5-352011, 2011.

Alley, R. B., Horgan, H. J., Joughin, I., Cuffey, K. M., Dupont, T. K., Parizek, B. R., Anandakrishnan, S., and Bassis, J.: A Simple Law for Ice-Shelf Calving, Science, 322, 1344, 2008.

Amundson, J. M. and Truffer, M.: A unifying framework for iceberg-calving models, J. Glaciol., 56, 822-830, 2010.
Balay, S., Buschelman, K., Eijkhout, V., Gropp, W., Kaushik, D., Knepley, M., McInnes, L. C., Smith, B., and Zhang, H.: PETSc Users Manual, Argonne National Laboratory, http://www.mcs. anl.gov/petsc/, 2008.

Bamber, J. L., Riva, R. E. M., Vermeersen, B. L. A., and LeBrocq, A. M.: Reassessment of the Potential Sea-Level Rise from a Collapse of the West Antarctic Ice Sheet, Science, 324, 901-903, doi:10.1126/science.1169335, 2009.

Bassis, J. N.: The statistical physics of iceberg calving and the emergence of universal calving laws, J. Geolog., 57, 3-16, 2011.

Benn, D. I., Hulton, N. R. J., and Mottram, R. H.: "Calving laws", 'sliding laws' and the stability of tidewater glaciers, Ann. Glaciol., 46, 123-130, 2007.

Bentley, C. R.: The Ross Ice shelf Geophysical and Glaciological Survey (RIGGS): Introduction and summary of measurments performed; Glaciological studies on the Ross Ice Shelf, Antarctica, 1973-1978, Antarc. Res. Ser., 42, 1-53, 1984.

Bueler, E. and Brown, J.: The shallow shelf approximation as a sliding law in a thermomechanically coupled ice sheet model, J. Geophys. Res., 114, F03008, 2009.

Bueler, E., Brown, J., and Lingle, C.: Exact solutions to the thermomechanically coupled shallow-ice approximation: effective tools for verification, J. Glaciol., 53, 499-516, 2007.

Cazenave, A., Dominh, K., Guinehut, S., Berthier, E., Llovel, W. Ramillien, G., Ablain, M., and Larnicol, G.: Sea Level Budget over 2003-2008: a reevaluation from GRACE space gravimetry, satellite altimetry and Argo, GPC, 56, 83-88, 2009.

Comiso, J. C.: Variability and Trends in Antarctic Surface Temperatures from In Situ and Satellite Infrared Measurements., J. Climate, 13, 1674-1696, 2000.

De Angelis, H. and Skvarca, P.: Glacier Surge After Ice Shelf Collapse, Science, 299, 1560-1563, 2003.

Doake, C. S. M.: Ice Shelf Stability, British Antarctic Survey, 1282 1290, 2001.

Doake, C. S. M., Corr, H. F. J., Skvarca, P., and Young, N. W. Breakup and conditions for stability of the northern Larsen Ice Shelf, Antarctica, Nature, 391, 778-780, 1998.

Dupont, T. K. and Alley, R. B.: Assessment of the importance of ice-shelf buttressing to ice-sheet flow, Geophys. Res. Lett., 32, 4503, 2005.

Dupont, T. K. and Alley, R. B.: Role of small ice shelves in sealevel rise, Geophys. Res. Lett., 33, 9503, 2006.

Glasser, N. F. and Scambos, T. A.: A structural glaciological analysis of the 2002 Larsen B Ice Shelf collapse, J. Glaciol., 54, 3-16, 2008.

Grosfeld, K. and Sandhäger, H.: The evolution of a coupled ice shelf-ocean system under different climate states, Glob. Planet. Change, 42, 107-132, 2004.

Hulbe, C. L., LeDoux, C., and Cruikshank, K.: Propagation of long fractures in the Ronne Ice Shelf, Antarctica, investigated using a numerical model of fracture propagation, J. Glaciol., 56, 459$472,2010$.

Humbert, A. and Steinhage, D.: The evolution of the western rift area of the Fimbul Ice Shelf, Antarctica, The Cryosphere, 5, 931944, doi:10.5194/tc-5-931-2011, 2011

Humbert, A., Kleiner, T., Mohrholz, C. O., Oelke, C., Greve, R., and Lange, M. A.: A comparative modeling study of the Brunt Ice Shelf/Stancomb-Wills Ice Tongue system, East Antarctica, J. Glaciol., 55, 53-65, 2009. 
Jansen, D., Kulessa, B., Sammonds, P. R., Luckman, A., King, E., and Glasser, N.: Present stability of the Larsen C ice shelf, Antarctic Peninsula, J. Geolog., 56, 593-600, 2010.

Jezek, K. C., Farness, K., Carande, R., Wu, X., and LabelleHamer, N.: RADARSAT 1 synthetic aperture radar observations of Antarctica: Modified Antarctic Mapping Mission, 2000, Radio Science, 38, 32-1, 2003.

Joughin, I.: Ice-sheet velocity mapping: a combined interferometric and speckle-tracking approach, Ann. Glaciol., 34, 195-201, 2002.

Joughin, I. and Padman, L.: Melting and freezing beneath FilchnerRonne Ice Shelf, Antarctica, Geophys. Res. Lett., 30, 1477, doi:10.1029/2003GL016941, 2003.

Kenneally, J. P. and Hughes, T. J.: The calving constraints on inception Quternary ice sheets, Quat. Internat., 95-96, 43-53, 2002.

Kenneally, J. P. and Hughes, T. J.: Calving giant icebergs: old principles, new applications, Antarctic Sci., 18, 409-419, 2006.

Khazendar, A., Rignot, E., and Larour, E.: Larsen B Ice Shelf rheology preceding its disintegration inferred by a control method, Geophys. Res. Lett., 34, L19503, 2007.

Khazendar, A., Rignot, E., and Larour, E.: Roles of marine ice, rheology, and fracture in the flow and stability of the Brunt/Stancomb-Wills Ice Shelf, J. Geophys. Res., 114, F04007, 2009.

Larour, E., Rignot, E., and Aubry, D.: Modelling of rift propagation on Ronne Ice Shelf, Antarctica, and sensitivity to climate change, Geophys. Res. Lett., 31, L16404, 2004.

Larour, E., Rignot, E., and Aubry, D.: Processes involved in the propagation of rifts near Hemmen Ice Rise, Ronne Ice Shelf, Antarctica, J. Glaciol., 50, 329-341, 2004.

Le Brocq, A. M., Payne, A. J., and Vieli, A.: An improved Antarctic dataset for high resolution numerical ice sheet models (ALBMAP v1), Earth System Science Data, 2, 247-260, 2010.

Liu, H., Jezek, K. C., and Li, B.: Development of an Antarctic digital elevation model by integrating cartographic and remotely sensed data: A geographic information system based approach, J. Geophys. Res., 104, 23199-23214, 1999.

Luckman, A., Jansen, D., Kulessa, B., King, E. C., Sammonds, P., and Benn, D. I.: Basal crevasses in Larsen C Ice Shelf and implications for their global abundance, The Cryosphere, 6, 113-123, doi:10.5194/tc-6-113-2012, 2012.

Lythe, M. B., Vaughan, D. G., and BEDMAP Consortium: A new ice thickness and subglacial topographic model of Antarctica, J. Geophys. Res., 106, 11335-11351, http://www.nerc-bas.ac.uk/ public/aedc/bedmap/bedmap.html, 2001.

Lythe, M. B., Vaughan, D. G., and BEDMAP Consortium: BEDMAP: A new ice thickness and subglacial topographic model of Antarctica, J. Geophys. Res., 106, 11335-11351, 2001.

MacAyeal, D. R., Rommelaere, V., Huybrechts, P., Hulbe, C. L., Determann, J., and Ritz, C.: An ice-shelf model test based on the Ross Ice Shelf, Ann. Glaciol., 23, 46-51, 1996.

MacAyeal, D. R., Scambos, T. A., Hulbe, C. L., and Fahnestock, M. A.: Catastrophic ice-shelf break-up by an ice-shelf-fragmentcapsize mechanism, J. Glaciol., 49, 22-36, 2003.

Martin, M. A., Winkelmann, R., Haseloff, M., Albrecht, T., Bueler, E., Khroulev, C., and Levermann, A.: The Potsdam Parallel Ice Sheet Model (PISM-PIK) - Part 2: Dynamic equilibrium simulation of the Antarctic ice sheet, The Cryosphere, 5, 727-740, doi:10.5194/tc-5-727-2011, 2011.
Morland, L. W.: Unconfined Ice-Shelf flow, in: Dynamics of the West Antarctic Ice Sheet, edited by: Van der Veen, C. J., and Oerlemans, J., 117-140, Cambridge University Press, 1987.

Paterson, W. S. B. and Budd, W. F.: Flow parameters for ice sheet modelling, Cold. Reg. Sci. Technol., 6, 175-177, 1982.

Pelto, M. S. and Warren, C. R.: Relationship between tidewater glacier calving velocity and water depth at the calving front, Ann. Glaciol., 15, 115-118, 1991.

Peskin, M. and Schroeder, D.: An Introduction to Quantum Field Theory, Addison-Wesley Publishing Company, 1995.

PISM-authors: PISM, a Parallel Ice Sheet Model: User's manual, http://www.pism-docs.org/wiki/lib/exe/fetch.php?media= manual.pdf, 2012.

Pollard, D. and Deconto, R. M.: Modelling West Antarctic ice sheet growth and collapse through the past five million years, Nature, 458, 329-332, 2009.

Pritchard, H. D. and Vaughan, D. G.: Widespread acceleration of tidewater glaciers on the Antarctic Peninsula, J. Geophys. Res., 112, F03S29, 2007.

Reeh, N.: On the calving of ice from floating glaciers and ice shelves, J. Glaciol., 7, 215-232, 1968.

Rignot, E., Casassa, G., Gogieneni, P., Rivera, A., and Thomas, R.: Accelerated ice discharge from the Antarctic Penninsular following the collapse of Larsen B Ice Shelf, Geophys. Res. Lett., 31, L18401, 2004.

Rignot, E., Mouginot, J., and Scheuchl, B.: Ice Flow of the Antarctic Ice Sheet, Science, 333, 1427-1430, doi:10.1126/science.1208336, http://www.sciencemag.org/ content/333/6048/1427.abstract, 2011.

Rist, M. A., Sammonds, P. R., Murrell, S. A. F., Meredith, P. G., Doake, C. S. M., Oerter, H., and Matsuki, K.: Experimental and theoretical fracture mechanics applied to Antarctic ice fracture and surface crevassing, J. Geophys. Res., 104, 2973-2988, 1999.

Rott, H., Rack, W., and Nagler, T.: Increased export of grounded ice after the collapse of northern Larsen ice shelf, Antarctic Peninsula, observed by Envisat ASAR, Geoscience and Remote Sensing Symposium, IEEE International, 1174-1176, 2007.

Saheicha, K., Sandhäger, H., and Lange, M. A.: Modelling the flow regime of Filchner-Shelfeis, FRISP Report No. 14, 58-62, 2006.

Scambos, T., Bohlander, J., Shuman, J. A., and Skvarca, P.: Glacier acceleration and thinning after ice shelf collapse in the Larsen B embayment, Antarctica, Geophys. Res. Lett., 31, L18402, 2004.

Schoof, C.: Ice sheet grounding line dynamics: Steady states, stability, and hysteresis, J. Geophys. Res., 112, F03S28, 2007.

Thomas, R., MacAyeal, D., Eilers, D., and Gaylord, D.: Glaciological Studies on the Ross Ice Shelf, Antarctica, 1972-1978, Glaciol. Geophys. Antarc. Res.-Ser., 42, 21-53, 1984.

Thomas, R., Rignot, E., Casassa, G., Kanagaratnam, P., Acuña, C., Akins, T., Brecher, H., Frederick, E., Gogineni, P., Krabill, W., Manizade, S., Ramamoorthy, H., Rivera, A., Russell, R., Sonntag, J., Swift, R., Yungel, J., and Zwally, J.: Accelerated SeaLevel Rise from West Antarctica, Science, 306, 255-258, 2004.

Van de Berg, W. J., Van den Broeke, M. R., Reijmer, C. H., and Van Meijgaard, E.: Reassessment of the Antarctic surface mass balance using calibrated output of a regional atmospheric climate model, J. Geophys. Res.-Atmos., 111, 11104, doi:10.1029/2005JD006495, 2006.

Vieli, A., Payne, A. J., Du, Z., and et al.: Numerical modelling and data assimilation of the Larsen B ice shelf, Antarctic Peninsula, 
R. Soc. Lond. Philos. Trans. A, 364, 1815-1839, 2006.

Vieli, A., Payne, A. J., Shepherd, A., and Du, Z.: Causes of precollapse changes of the Larsen B ice shelf: Numerical modelling and assimilation of satellite observations, Earth Planet. Sci. Lett., 259, 297-306, 2007.

Weertman, J.: Stability of the junction of an ice sheet and an ice shelf, J. Glaciol., 13, 3-11, 1974.

Weis, M., Greve, R., and Hutter, K.: Theory of shallow ice shelves, Continuum Mech. Thermodyn., 11, 15-50, 1999.
Winkelmann, R., Martin, M. A., Haseloff, M., Albrecht, T., Bueler, E., Khroulev, C., and Levermann, A.: The Potsdam Parallel Ice Sheet Model (PISM-PIK) - Part 1: Model description, The Cryosphere, 5, 715-726, doi:10.5194/tc-5-715-2011, 2011.

Winkelmann, R., Levermann, A., Frieler, K., and Martin, M. A.: Uncertainty in future solid ice discharge from Antarctica, The Cryosphere Discuss., 6, 673-714, doi:10.5194/tcd-6-673-2012, 2012. 